\title{
Educação e lazer: analisando os contextos do Programa Escola Integrada de Belo Horizonte ${ }^{1}$
}

\author{
Education and leisure: analyzing the Integrated \\ School Program in Belo Horizonte
}

\section{Educación y ocio: analizando los contextos del Programa Escuela Integrada de Belo Horizonte}

\author{
Marcília de Sousa Silva* \\ Hélder Ferreira Isayama**
}

\begin{abstract}
Resumo: Este artigo objetiva analisar as concepções de lazer e educação que permeiam os documentos do Programa Escola Integrada do município de Belo Horizonte. A análise foi fundamentada no Policy cycle approach e enfatizada nos contextos de influência e produção de textos da política. Dessa forma, investigamos a formação da agenda política, o Projeto Político Pedagógico do programa e o Plano Estratégico BH 20102030. O contexto da política não se organiza de forma linear, mas é um processo de interação de interesses de grupos. Com o discurso do enfrentamento do fracasso escolar, revelado pelos índices de avaliação de rendimento e de fluxo (aprovação, repetência e evasão) dos alunos, os documentos da Escola Integrada anunciam a educação e lazer como formas de produção, estreitando as relações do público e privado. O direito à educação está restrito ao acesso e permanência das crianças e jovens na escola, sem que se amplie uma perspectiva para a universalização e qualidade. Os documentos abordam o lazer numa visão que o reduz à construção e manutenção de equipamentos e à ideia de atividade.
\end{abstract}

Palavras-chave: Educação. Lazer. Escola Integrada.

\begin{abstract}
This article aims to analyze the concepts of leisure and education that permeate the documents in the Integrated School Program in Belo Horizonte. The analysis was based on the Policy cycle approach and emphasized the contexts of influence and the policy text production. Thus, the formation of the political agenda, the Political Pedagogical Project Program and the Strategic Plan 2010-2030 BH were

\footnotetext{
${ }^{1}$ Este artigo foi produzido a partir de estudo desenvolvido no Programa de Pós-Graduação em Estudos do Lazer da Escola de Educação Física Fisioterapia e Terapia Ocupacional da Universidade Federal de Minas Gerais (UFMG).

"Professora de Educação Física da Prefeitura de Belo Horizonte. Doutoranda em Estudos do Lazer na Universidade Federal de Minas Gerais (UFMG). E-mail: <marciliasousasilva@yahoo.com.br>

** Professor do Programa de Pós-Graduação em Lazer da Universidade Federal de Minas Gerais (UFMG). E-mail: <helderisayama@yahoo.com.br>
} 
investigated. The policy context is not organized in a linear fashion; it is a process of groups of interest interaction. With the discourse of coping with school failure, revealed by the students' yield and flow evaluation indices (approval, repetition and dropout), the Integrated School education documents announce education and leisure as forms of production, strengthening links between public and private. The right to education is restricted to children's and youth's access and permanence in school without creating a perspective of universalization and quality. The documents address the leisure with a simplistic view of construction and maintenance of equipment and the idea of activity. Keywords: Education. Leisure. Integrated School.

Resumen: Este artículo tiene como objetivo analizar las concepciones de ocio y la educación que impregnan los documentos del Programa Escuela Integrada de Belo Horizonte. El análisis se basa Policy cycle approach y enfatiza los contextos de influencia y la producción de textos de política. De esa forma investigamos la formación de la agenda política y el proyecto político pedagógico del Programa y el Plan Estratégico BH 2010-2030. El contexto político no se organiza de forma lineal, es un proceso de interacción de los intereses de los grupos. Con el discurso de afrontar el fracaso escolar, revelado por los índices de evaluación de rendimiento y de flujo (aprobación, repitencia y deserción escolar) de los estudiantes, los documentos de la Escuela Integrada anuncian la educación escolar y el ocio como formas de producción, estrechando las relaciones de lo público y privado. El derecho a la educación se restringe al acceso y la permanencia de los niños y jóvenes en la escuela, sin que se amplíe a la universalización y calidad. Los documentos abordan el ocio en una visión que lo reduce a la construcción y el mantenimiento de equipamientos y a la ideia de actividad.

Palabras clave: Educación. Ocio. Escuela Integrada.

\section{Introdução}

O presente trabalho aborda questões relativas aos contextos na constituição do Programa Escola Integrada da rede de ensino municipal de Belo Horizonte. A análise fundamentada no ciclo de políticas (Policy cycle approach) e enfatizada no contexto de influência e produção de texto apresenta instrumentos para uma abordagem crítica da trajetória política do referido programa. O ciclo de políticas é um referencial analítico de políticas educacionais proposto por Ball (1994) e que auxilia na análise da trajetória de políticas e programas educacionais, contemplando os contextos de influência, de produção de textos, de prática e de resultados/efeitos. Este trabalho evidencia os contextos de influência e de produção de textos do Programa Escola Integrada, objetivando a compreensão das 
concepções de educação e lazer nos documentos referentes ao plano estratégico de governo e ao projeto pedagógico do programa.

Nesse sentido, as discussões apresentadas resultam de revisão bibliográfica sobre a relação entre Estado e políticas educacionais e de pesquisa documental realizada nos referenciais do Projeto Escola Integral. Dessa forma, analisamos a proposta político-pedagógica, que, após avaliação da Secretaria de Educação do Município de Belo Horizonte, foi redimensionada no que se refere aos recursos humanos e financeiros, mas não sofreu alterações nos outros itens de seu corpo teórico, configurando-se como a atual proposição do Programa Escola Integrada. O Plano Estratégico de BH 2010-2030 foi selecionado para análise em função das diretrizes apontadas para a educação e lazer na cidade as quais estabelecem metas a médio e longo prazo.

A abordagem do ciclo de políticas traduz a complexidade e ou contradições da política educacional e caracteriza-se pelo dinamismo e flexibilidade e pela rejeição da concepção tradicional de política que assume uma ordem e linearidade em sua proposição (MAINARDES; MARCONDES, 2009). Na apropriação dessas ideias, entendemos que as políticas apresentam constructos diferenciados que as aproximam de uma constituição por meio de regulação e imperativos, de princípios e valores e de esforços coletivos em níveis de interpretação.

Compartilhamos com Ball (2006) a ideia de que a política não se organiza de forma linear, mas é um processo de interação de interesses de grupos, mediada pela prática e, por isso, exige uma análise que supere a fragmentação e considere que os elementos constituintes interagem nas realidades históricas. Considerando a atualidade, Ball (2011) revela que há uma profunda transformação nos princípios da provisão social e que, como tal, há mudanças nos sistemas de financiamento, nos papéis e estilos de administração, nas relações sociais e nas condições das organizações públicas. Assim, nesses contextos, são construídos os discursos que servem de base para a elaboração das políticas, e é neles que os grupos de interesses operam, buscando fortalecer seus argumentos e dar legitimidade às suas ideias.

$\mathrm{Na}$ construção da relação entre Estado e educação não é possível ignorar as questões socioeconômicas que são também influenciadoras das políticas. Há uma correlação nas questões referentes à distribuição de renda e riqueza do país e sua interferência no acesso e permanência dos estudantes na escola (CURY, 2002). Oliveira (2011) reitera que as políticas educacionais estão sujeitas tanto à lógica daqueles que a julgam promotora do desenvolvimento econômico quanto à daqueles que a percebem como um processo de formação humana.

Ball (1994) descreve que no Estado há diferença entre política ideológica, controle de agenda, processo de influência e produção de texto porque há jogo de interesses que podem legitimar certas agendas. Para o autor, 
[...] é crucial reconhecer que as políticas em si mesmas, os textos, não são necessariamente claros ou fechados, ou completos. Os textos são produtos de acordos em vários estágios (em pontos de influência inicial, nas micro políticas da formulação legislativa, no processo parlamentar e nas políticas e micro políticas de articulação de grupos de interesse). Eles são caracteristicamente os frutos de múltiplas (mas circunscritas) influências e agendas. (BALL, 1994, p. 16).

As políticas educacionais, então, são compreendidas como ações públicas resultantes da responsabilidade do Estado e da participação da sociedade, com o foco mais específico na escola. Isso porque a educação extrapola o contexto das instituições escolares, quando compreendida a partir de um conceito amplo. Conforme Oliveira (2010a), educação é tudo que se aprende socialmente e é resultante do ensino, observação, repetição, produção, reprodução, participação, experimentação, inculcação. As políticas públicas educacionais, portanto, referem-se às intervenções do Estado no sentido de direcionar o processo educativo e o controle da prática educacional institucionalizada. Nesses termos, a educação é política pública de caráter social e de responsabilidade do Estado e apresenta propensão a interferências, influências e articulações de diferentes atores (sociedade civil, instituições financeiras, governos).

$\mathrm{Na}$ educação, algumas estratégias de intervenção estatal trazem, além da desigualdade econômica, a desigualdade social como "questão de fundo", as quais norteiam os projetos e programas de governo implantados no espaço escolar para o atendimento de crianças, jovens e adultos. Fleury (2010) revela que a desigualdade social é também uma ferramenta que delineia as políticas públicas, e, por isso, as políticas sociais são designadas como processos de intervenção de caráter distributivo, que buscam assegurar os direitos da cidadania e a promoção da justiça social e o bem-estar dos membros da comunidade. Nesse sentido, Oliveira (2010a) aponta que as políticas educacionais foram dirigidas à noção de justiça social, de promoção da igualdade entre os indivíduos, independente de sua condição econômica. Assim, a educação é apontada como um elemento de desenvolvimento que se configura na busca de eficiência econômica, promoção da justiça social e da cidadania.

A educação, enfim, constitui-se em um campo que guarda as especificidades dos processos educativos e que sustenta as políticas de reformas no âmbito da escola. Derouet (2010) aponta que os objetivos das políticas educacionais se superpõem, mas há o destaque para o referencial da globalização, que é a competição (lugar) do país no cenário mundial em superposição à justiça social, baseada na igualdade de chances. Esses objetivos das políticas educacionais se materializam em reformas que evidenciam as transformações do papel do Estado e a dinâmica de construção de intervenções nos espaços escolares. Tais reformas também se baseiam em imperativos financeiros consolidados por agências mundiais 
que exercem influência na educação. Entram em cena as agências ${ }^{1}$, cuja intenção é a mobilização de diferentes países para debater e enfrentar os problemas que atingem a todos, sem distinção; por isso, traçam propostas e metas que provocam reformulações na educação, em seus currículos e avaliações, articulando um ‘discurso' ideológico. Contudo, também é necessário ressaltar que há variação na predisposição de regimes políticos nacionais para aceitar essas influências globais ou para retomar suas tradições, o que, de acordo com Ball (2004), significa que há diversidade na interação da agenda neoliberal com os modos de intervenção do Estado.

Esse panorama deixa claro que a articulação das políticas educacionais com as demais políticas não somente destaca uma concepção de educação centrada no exercício da cidadania, dos direitos, como também uma necessidade de eficácia no desempenho social e econômico do país, importante no cenário competitivo mundial. Nessa lógica, o debate contemporâneo das políticas educacionais tem proporcionado alterações na legislação referentes à ampliação dos anos de escolaridade, à reestruturação da gestão de recursos financeiros para educação, à execução de avaliações sistemáticas, à constituição de planos de governos, às intervenções na cultura escolar, dentre outros.

No Brasil, há um contexto político favorável a esse debate, pois se alia a esse movimento a instituição, em 2007, da Diretoria de Educação Integral, Direitos Humanos e Cidadania da Secretaria de Educação Continuada, Alfabetização e Diversidade do Ministério da Educação (MOLL, 2011). Suas intervenções são orientadas para o aumento da jornada de permanência do aluno na escola e o para o desenvolvimento de atividades culturais, esportivas e de lazer, operacionalizadas por programas de financiamentos.

\section{Escola em Tempo Integral no Cenário Brasileiro}

O tempo escolar integral é compreendido como um caminho para a garantia da qualidade da educação, concebida como resultado de variáveis diferenciadas que interferem nos processos educativos, tais como adequação de espaços e infraestrutura, materialidade, formação dos sujeitos envolvidos na ação, gestão. Outras variantes são a flexibilização e adequação de horários, que também estão associadas às demais questões que intervêm na escola com vistas ao patamar de qualidade desejado. Nesse sentido, a escola em tempo integral é caracterizada pela articulação da educação com o aumento do tempo

\footnotetext{
${ }^{1}$ Ball (2004) relata que agências como o Banco Mundial, Fundo Monetário Internacional (FMI), Organização das Nações Unidas para a Educação, a Ciência e a Cultura (UNESCO), Mercado Comum do Sul (MERCOSUL), Fundo das Nações Unidas para a Infância (UNICEF), Organização Mundial do Comércio (OMC), a Organização para a Cooperação e Desenvolvimento Econômico (OCDE), dentre outras, participam da construção e disseminação de novas relações entre educação e economia.
} 
de permanência na escola e pela ênfase no desenvolvimento integral de seus participantes. Ressaltamos que a educação integral refere-se ao desenvolvimento 'total' ${ }^{2}$ dos sujeitos e não está restrita à instituição escolar. Assim, neste estudo, a denominação utilizada de Escola em Tempo Integral considera a dimensão de 'educação integral em escola de tempo integral', visto que, ao tratar de Escola de Tempo Integral, a ênfase é dada na categoria tempo numa perspectiva cronológica de extensão e não o caráter de tempo social.

Paro (2009) destaca que a ideia de educação integral está atrelada à ampliação de tempo, pois entende que "nem se precisará levantar a bandeira do tempo integral porque, para fazer-se a educação integral, esse tempo maior necessariamente terá que ser levado em conta" (PARO, 2009, p. 19).

Essa argumentação permite compor uma reflexão sobre a função da escola em tempo integral, ou seja, ser integral permite reforçar formas de controle social ou de desenvolver uma formação democrática, embasada na consciência de uma realidade social e suas possíveis transformações.

O tempo integral da escola pública era considerado por Darcy Ribeiro, nos anos de 1980, como a fórmula para iniciar "as crianças nos códigos de sociabilidade, tratamento, relacionamento e preparo para a vida em sociedade" (BOMENY, 2009, p. 114). Assim, o aluno era estimulado a permanecer na instituição em tempo integral para qualificar seu desenvolvimento, por meio de diversas atividades assistidas. Revisitar essa história é importante para tratar da trajetória da educação de tempo integral, que é construída nos textos das legislações brasileiras. O traçado na constituição das leis que regulamentam as ações de ampliação da jornada escolar no processo de educação integral justificase pelo reconhecimento de que a escola de (em) tempo integral brasileira legitimada e materializada em políticas públicas - precisa ser analisada, criticada e avaliada para retomar ou traçar novos pressupostos e diretrizes para as ações educativas.

Menezes (2009) destaca que existe nos textos legislativos uma concepção de educação como direito e conjugada à integralidade da formação das pessoas ('pleno desenvolvimento'). No percurso da legislação educacional, destaca-se a

\footnotetext{
${ }^{2}$ Tonet (2006) faz crítica aos termos desenvolvimento total/formação integral revelando que diz respeito ao acesso pelos indivíduos aos bens (materiais e espirituais) necessários à sua autoconstrução, o que implica emancipação humana. Para garantir esse acesso é exigida uma forma de sociedade a qual requer um tipo de trabalho que elimine a exploração e dominação do homem pelo homem. Nesse sentido, o autor reitera que baseado no capital "a realização de uma formação integral jamais pode se transformar em uma efetividade" (TONET, 2006, p. 17). Contudo, Moraes (2009) retrata que para se pensar em educação integral deve-se, primeiro, retomar os conceitos de educação da gênese do movimento operário do séc. XIX, ou seja, a construção de uma sociedade de caráter socialista, e, segundo, problematizar a realidade dessa formação no bojo das potencialidades e obstáculos da contemporaneidade.
} 
Lei de Diretrizes Bases da Educação Nacional (LDBEN) ${ }^{3}$, que prevê a estratégia de tempo escolar integral no art. 34: "A jornada escolar no ensino fundamental incluirá pelo menos quatro horas de trabalho efetivo em sala de aula, sendo progressivamente ampliado o período de permanência na escola". E, no art. 32, a legislação trata da obrigatoriedade do ensino fundamental estabelecendo orientações para a formação básica do cidadão. Essa legislação estabelece que a União é responsável por elaborar o Plano Nacional de Educação em colaboração com os Estados, Distrito Federal e Municípios e em sintonia com a Declaração Mundial sobre Educação para Todos ${ }^{4}$.

Alicerçado no Plano de Metas Compromisso Todos pela Educação ${ }^{5}$, o Ministério da Educação lança o Plano de Desenvolvimento da Educação (PDE) ${ }^{6}$ visando à qualidade da educação baseada no Indicador de Desenvolvimento da Educação Básica (IDEB) ${ }^{7}$. O PDE atrelou a permanência na escola à qualidade do ensino e instituiu um instrumento para medir a qualidade de cada escola e de cada rede de ensino.

Considerando os indicadores, algumas políticas educacionais implantadas pelos governos federal, estadual e municipal apontam para caminhos alternativos na direção de uma nova ordem escolar e social, principalmente no que se refere à ampliação do tempo destinado à escola. Essas políticas retratam uma pluralidade de projetos e programas, nos quais as instâncias governamentais assumem a possibilidade de melhorar as condições de vida dos sujeitos. Seguindo esse contorno, é elementar que a escola em tempo integral tenha determinada função na comunidade, dando forma à condição igualitária e de equidade para aqueles

\footnotetext{
${ }^{3}$ LDBEN - Lei no $.9 .394 / 96$ de 20 de dezembro de 1996, que estabelece as diretrizes e bases da educação nacional. Sancionada em 12 de dezembro de 1996, pelo Presidente Fernando Henrique Cardoso e pelo Ministro da Educação Paulo Renato de Souza, tendo como relator Darcy Ribeiro.

${ }^{4}$ Nos anos 90, em Jonthien/Tailândia, foi realizada uma conferência patrocinada pela Organização das Nações Unidas para a Educação, Ciência e Cultura (UNESCO), o Programa das Nações Unidas para o Desenvolvimento (PNUD), o Fundo das Nações Unidas para a Infância (UNICEF) e o Banco Mundial. No evento foi aprovada a Declaração Mundial sobre Educação para Todos.
}

${ }^{5}$ O Plano de Metas Compromisso Todos pela Educação, disposto no Decreto no 6.094 de 24 de abril de 2007. Este Plano resulta de um movimento que, apresentando-se como iniciativa da sociedade civil, constituiu-se, de fato, por um aglomerado de grupos empresariais (SAVIANI, 2007).

${ }^{6} \mathrm{PDE}$ é uma política pública, um conjunto de medidas e metas, estabelecido simultaneamente ao decreto 6.094 de 24 de abril de 2007. Após a adesão ao Compromisso Todos pela Educação, os municípios devem elaborar, para o período de quatro anos, o Plano de Ações Articuladas (PAR), que se constitui no planejamento da política educacional do município, que tem por referência o cumprimento das metas.

${ }^{7}$ Saviani (2007) retrata que o IDEB é um instrumento calculado com base em dois tipos de informações: a) as informações sobre rendimento escolar (aprovação, reprovação e abandono) do Censo Escolar da Educação Básica; e b) as informações sobre o desempenho dos estudantes em exames padronizados elaborados pelos sistemas Instituto Nacional de Estudos e Pesquisas Anísio Teixeira (INEP), Sistema de Avaliação da Educação Básica (SAEB) e Prova Brasil. É a partir do índice alcançado pelos entes federativos que a União oferece apoio técnico e financeiro, previstos na Constituição. 
que dela usufruem. Ao considerar, então, que há um esforço para a ampliação do acesso democrático à escola pública de ensino básico e que a sociedade brasileira vem debatendo e traçando experiências de expansão da jornada escolar diária, é importante pensar o que leva a essas ações de ampliação do tempo, que podem ser balizadas por diferentes concepções sobre a escola em tempo integral.

Maurício (2009) revela que, para se pensar numa escola em tempo integral que projete uma educação integral, é necessário atentar-se para alguns condicionantes. O primeiro deles é que basear essa experiência no princípio de tirar a criança da rua pode levar à ideia de enclausuramento, que inevitavelmente não contribui para uma formação integral ${ }^{8}$. O segundo é que a escola em tempo integral deve ser um espaço investigativo onde a convivência com as diversas culturas, tensões e conflitos seja compreendida como possibilidade de desenvolvimento. Em seguida, que a escola enfatize a aprendizagem e o uso de recurso das diversas linguagens e, finalmente, que a escola em tempo integral deve ser considerada necessariamente como uma política de Estado.

As justificativas para a ampliação do tempo escolar são diversas, e as correntes podem ser fundamentadas em concepções autoritárias e assistencialistas ou concepções democráticas e emancipatórias (CAVALIERE, 2007). Isso significa que cada política pública que se materializa na escola em tempo integral pode apresentar tendências para uma ou outra corrente ideológica, ou mesmo apresentar um hibridismo no seu desenho. As experiências de escola em tempo integral apresentam denominações e concepções diversas e têm se configurado sob a responsabilidade de secretarias de educação, provavelmente sob a influência das legislações e políticas federais orientadoras do tempo integral.

Dentre as legislações, este estudo aponta o PDE, que é composto por trinta ações abordando as áreas de atuação do Ministério da Educação e abrangendo os níveis e modalidades de ensino, além das medidas de apoio e infraestrutura. Portanto, a formulação do PDE trouxe à tona a complexidade do tema sobre escola em tempo integral, na medida em que ele estabelece como uma das ações complementares para a educação básica, um programa de caráter interministerial - o Programa Mais Educação.

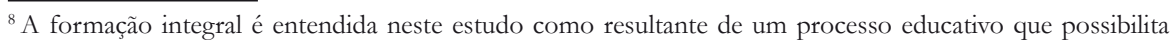
ao homem tornar-se apto para olhar, perceber e compreender as coisas e o outro, constituir sua identidade e distinguir e reconhecer as semelhanças e diferenças entre si e o outro e o mundo e como possibilidade do homem se fazer "sujeito, ou seja, não meramente um ator, mas um autor, autor de sua própria humanidade" (PARO, 2009, p. 16).
} 


\section{Mais Educação e o fomento das experiências de escola em tempo integral}

O Programa Mais Educação foi criado em 2007 pela Portaria Interministerial $^{9} \mathrm{n}^{\mathrm{o}} 17 / 2007$ e regulamentado por Decreto Presidencial 7083/2010, embasado nos planos de ações do PDE, com o propósito de contribuir para a diminuição das desigualdades educacionais e para a valorização da diversidade cultural brasileira. O programa propõe a ampliação da jornada escolar diária e dos espaços e oportunidade de aprendizagem, desenvolvendo atividades educativas nos campos do esporte, arte, lazer, educação, cultura. As orientações do Mais Educação indicam que os espaços extramuros da escola são também educativos e apontam para a superação das desigualdades educacionais e para a proteção e assistência social, sugerindo outros protagonistas na educação, além dos professores.

Em relação à ação dos sujeitos na educação, uma questão interessante é o debate sobre a formação necessária para o trabalho docente, entendido como processo de ensino formal somado às outras atividades inerentes à educação (OLIVEIRA, 2010b). Essa discussão é fundamental, pois os sujeitos que atuam nessas experiências podem permanecer desvinculados das propostas pedagógicas da escola. Dessa forma, essa separação pode caracterizar duas escolas em uma, em que as propostas pedagógicas não se cruzam e não há diálogos. Moll (2011) aponta que é preciso superar esse paralelismo que impossibilita interseções entre um turno e outro. A integração curricular desconstrói a ideia de que o tempo integral represente outra escola ou um conjunto de atividades extracurriculares.

É necessário destacar que o Mais Educação aponta como princípio o envolvimento de novos atores, principalmente organizações não governamentais e da esfera privada, cuja participação na escola traduz em novas funções institucionais. Portanto, abordar a educação integral é buscar novos significados para a escola, repensando, em especial, seu projeto político-pedagógico.

O programa apresenta uma proposta de integração entre campos de conhecimentos e de expressão das diferentes linguagens (verbal, matemática, artística, corporal, tecnológica), utilizando uma metodologia de macrocampos. Denominados como Acompanhamento Pedagógico, Educação Ambiental, Esporte e Lazer, Direitos Humanos em Educação, Cultura e Artes, Cultura Digital, Promoção da Saúde, Comunicação e uso de Mídias, Investigação no Campo das Ciências da Natureza e Educação Econômica, cada um desses macrocampos agrega um conjunto de atividades específicas. As escolas se

\footnotetext{
${ }^{9}$ O Programa Mais Educação foi instituído por ação conjunta do Ministério da Educação, Ministério do Desenvolvimento Social e Combate a Fome, Ministério da Ciência e Tecnologia, Ministério do Esporte, Ministério do Meio Ambiente, Ministério da Cultura, Ministério da Defesa e a Controladoria Geral da União.
} 
inscrevem no programa e fazem as escolhas de diferentes macrocampos, contemplando obrigatoriamente o Acompanhamento Pedagógico. De acordo com o Ministério da Educação, acrescentam-se a essa obrigatoriedade as orientações para o atendimento prioritário de estudantes em defasagem idade/ ano de escolaridade, beneficiários do Programa Bolsa Família e integrantes de localidades onde há histórico de evasão e repetência. A obrigatoriedade do campo pedagógico e prioridade do atendimento sugerem que o programa apresenta como princípio o desenvolvimento/aprendizagem do aluno e sua permanência na escola. Porém o programa limita o direito de participação de todos os alunos matriculados na rede pública de ensino ao delinear a prioridade no atendimento, contrariando, de certa forma, o direito constitucional.

O baixo IDEB e os territórios marcados por situação de vulnerabilidade social são priorizados na adesão ao programa. Portanto, a concepção de educação integral pautada nesse programa baseia-se no "binômio educação - proteção social” (SABOYA, 2012, p. 38). Desse modo, o Programa Mais Educação apresenta no bojo de seus princípios indícios de novas formas de gerenciar a instituição escolar, pois ela se torna central no processo de gestão e implementação. Por certo, a articulação da escola com sua comunidade é desejável e importante para a construção de seu projeto político pedagógico, porém os vínculos com a esfera privada podem representar uma mudança em relação às responsabilidades estatais com a escola em tempo integral.

Em Minas Gerais, baseadas na matriz referencial do Programa Mais Educação, algumas experiências foram implantadas, e a rede de ensino municipal da capital mineira implementou o Programa Escola Integrada com propósito de agregar o entorno da escola como espaço educativo e, assim, possibilitar melhoria na qualidade da educação.

\section{A Escola Integrada: princípios e apontamentos}

A Escola Integrada, assim como outras experiências de ampliação de tempo da rede municipal de ensino de Belo Horizonte, foi baseada na proposta política e pedagógica do município, denominada Projeto Escola Plural. Esse modelo, lançado em 1994, concebia outra ordem na proposta curricular como alternativa para o enfrentamento do fracasso escolar:

A proposta de Escola Plural pretende sintonizar-se com as experiências emergentes na Rede que apontam para um diagnóstico mais global dos problemas e para uma intervenção coletiva mais radical: intervir nas estruturas excludentes do sistema escolar e na cultura que legitima essas estruturas excludentes e seletivas. (PREFEITURA DE BELO HORIZONTE, 2002, p. 13). 
Para Saraiva e Costa (2010), a Escola Plural era uma política voltada para equidade, ao incorporar a preocupação com a diversidade cultural dos sujeitos, provenientes das famílias pobres, excluídos do sistema educacional tradicional. Essa proposta propunha a valorização das experiências educacionais não escolares dos alunos, difundindo a ideia "de que a educação é um direito e não mérito" (SARAIVA; COSTA, 2010, p. 26). Nesse contexto, apresenta avanços ao pensar uma educação adequada aos tempos em que todos têm direito a uma formação integral (SECRETARIA MUNICIPAL DE EDUCAÇÃO, 2010). Segundo Moreira (2000), o Projeto Escola Plural focaliza o aluno que passa a ser elemento ativo no processo de produção do conhecimento.

Nessa abordagem, a Escola Plural salientou o desafio de reconhecer os sujeitos do interior da escola e as desigualdades, assim como o de romper com a estrutura escolar que fragmentava e compartimentalizava saberes. Para tal, o projeto apresenta eixos norteadores das intervenções, que indicam uma ressignificação do espaço e tempo escolar e seus processos formativos (PREFEITURA MUNICIPAL DE BELO HORIZONTE, 2002). Nas suas diretrizes percebe-se a intenção de discutir a escola como espaço de produção e manifestação cultural.

Além disso, a Prefeitura de Belo Horizonte (2002) sinaliza para a reorganização tempo escolar quando discute que há uma tentativa de alargá-lo, contemplando as vivências e manifestações culturais e, ainda, abrindo a escola para a comunidade. Assim, alargar os tempos diz respeito à não priorização de conteúdos curriculares, ou seja, possibilitar que a escola seja também um espaço para os conteúdos de matriz cultural.

Moreira (2000) analisa que o Projeto Escola Plural romperia a lógica hierárquica de disciplinas, se os eixos transversais propostos (cidadania, meio ambiente, etnia, sexualidade, diversidade cultural, gênero, consumo) constituíssem o currículo. Dessa forma, esses saberes corresponderiam a elementos do conhecimento que atravessariam as diversas áreas e disciplinas e permitiriam visualizá-los como expressão da função socializadora e cultural da escola.

É nesse contexto que surge o Projeto Escola Integral, criado em 2006 pela Secretaria Municipal de Educação (SMED) e caracterizado como uma política de continuidade, pois se fundava nos princípios da Escola Plural. Assim, o projeto buscava o desenvolvimento das competências individuais, sociais, produtivas e cognitivas dos estudantes matriculados, visando a melhorias na aprendizagem e no nível de escolaridade e, consequentemente, no sucesso pessoal e escolar.

O Projeto Escola Integral emerge como um plano piloto, implementado em seis escolas municipais; após avaliação no ano de 2007, foi ampliado o número de escolas em tempo integral. Como resultado da experiência piloto, a proposta político-pedagógica foi reformulada, apresentando modificações em 
sua denominação. A nova versão, então, apresenta-se como Programa Escola Integrada e aponta reformulações no que se refere aos profissionais responsáveis pela execução, inclusive com a criação do chamado agente cultural. A justificativa para mudança do nome do programa foi a necessidade de redimensionar a concepção de tempo integral para a ideia de escola integrada, considerando a educação um direito de todos e abrangendo todas as dimensões formativas do sujeito (SECRETARIA MUNICIPAL DE EDUCAÇÃO, 2007).

A Escola Integrada foi formatada para atender crianças e jovens por meio de ampliação da jornada escolar diária e está implantada nas nove regionais administrativas da Prefeitura de Belo Horizonte (PBH): Barreiro, Nordeste, Oeste, Centro-sul, Noroeste, Pampulha, Leste, Norte e Venda Nova. Atualmente, o programa está presente nas escolas municipais, e a participação dos alunos matriculados ocorre por adesão das famílias, o que compromete tanto a universalização no atendimento, quanto a frequência dos alunos nas atividades diárias. A adesão pode evidenciar as necessidades das famílias, a credibilidade ao programa, a satisfação e confiança da comunidade na proposta.

De acordo com Cardoso (2012, p. 103),

Embora a SMED anuncie que atende a milhares de estudantes, número bem superior ao número que as Turmas de Tempo Ampliado atendiam, o programa não é universalizado na RME-BH e nem mesmo nas escolas onde funcionam. Só uma parcela dos estudantes da RME-BH frequentam as atividades da Escola Integrada. Não há espaço físico suficiente para atender a todos os alunos.

Por outro lado, se o espaço físico da escola não atende à demanda do programa, há também uma situação de indisponibilidade ou inadequação dos espaços alternativos em muitos bairros da cidade. Mesmo que o programa tenha como referência os princípios da Carta das Cidades Educadoras, que sugerem a construção de uma rede social educadora e o desenvolvimento do potencial educativo da cidade, extrapolar os muros da escola pode tornar-se um fator limitante em comunidades onde os espaços alternativos, a segurança, a mobilidade são precários. Essas condições restringem a reinvenção ou ressignificação dos espaços da cidade pelos estudantes, pois se transformam em territórios inseguros e desacreditados.

A proposta da Escola Integrada, além de considerar o espaço da comunidade, estabelece uma ampliação da jornada escolar diária de quatro horas e 20 minutos para nove horas. O primeiro é organizado para o desenvolvimento das ações pedagógicas pelos docentes da instituição escolar, garantindo horas de "trabalho efetivo em sala de aula", acrescido dos 20 minutos de recreio diário, e o tempo de quatro horas e 40 minutos organizado em oficinas, alimentação e mobilidade para diferentes espaços. 
No que se refere às ações, a Coordenação do Programa Escola Integrada (2008, p. 22) relata que a carga horária ampliada tem como proposta o desenvolvimento de "atividades de diferentes áreas do conhecimento, formação social e pessoal, lazer, esportes, cultura e artes, acompanhamento pedagógico, desenvolvidas em oficinas que completam o currículo de forma a integrar as diversas dimensões formadoras do ser humano". As ações educativas são desenvolvidas por agentes culturais e monitores universitários, e a coordenação desses trabalhos é feita por um professor pertencente ao quadro administrativo da escola (professor comunitário). Existe, também, um monitor e coordenador de núcleo do Programa Segundo Tempo (PST), responsáveis pela oficina voltada para o esporte, monitorados por uma equipe ligada ao Ministério do Esporte.

Além disso, há, também, o papel de coordenação geral e regional, que são professores efetivos da rede de ensino em função administrativa na SMED e na Regional, respectivamente, os quais são responsáveis pelo acompanhamento do programa em diversas escolas e pela regulação e mediação de demandas de ampliação da oferta, recursos financeiros e negociações junto à SMED.

Dessa forma, o trabalho docente, compreendido como o trabalho específico do professor em sala de aula, a atenção e cuidado com o aluno e todas as outras atividades inerentes à educação é realizado por outros sujeitos que não são professores da escola. Isso exige, segundo Cavaliere (2007, p. 1031), um aumento de "responsabilidades de planejamento, controle e avaliação, caso contrário pode-se transformar perigosamente o sistema escolar em terra de ninguém". Coelho (2010) aponta que, além dos exíguos espaços para realização das oficinas, a sobrecarga do trabalho do professor comunitário e a pouca interação com os demais professores da escola, também as condições precárias de trabalho dos agentes e monitores e as formas de ingresso precisam ser superadas.

A Escola Integrada tem o Programa Mais Educação como referência para seu planejamento, tanto no que se refere ao arcabouço teórico quanto ao apoio financeiro dado às instituições que realizam ações socioeducativas. O programa propõe articulação com variadas instituições, como espaços de ensino superior, organizações não governamentais, fundações sociais, associações, fundamentada na construção de uma rede. Porém, quando há centralidade na ação do gestor da escola e do professor comunitário, o diálogo efetivo com essas instituições pode não ocorrer. Tal situação supõe uma construção política de forma unilateral e vertical, de cima para baixo, o que provoca insatisfação na comunidade escolar.

Para Cardoso (2012), não fazer parte do projeto maior da escola provoca um estranhamento e um sentimento de não autoria dos docentes, o que também leva a um mal-estar entre os professores da escola e os sujeitos envolvidos na execução do programa. Diz o autor: 
A Escola Integrada perde a oportunidade de desenvolver uma prática educativa mais ampla, mais integral. A potencialidade educativa e de socialização dos espaços escolares e não escolares, dos docentes e não docentes não se somam, não se articulam, não produzem sinergia em favor da infância e da adolescência popular. (CARDOSO, 2012, p. 105).

$\mathrm{Na}$ tentativa de promover a relação escola-comunidade, o programa foi divulgado nas mídias apresentando uma proposta de formação educacional diferenciada, inspirado no lema 'Para as Escolas da prefeitura, Belo Horizonte é uma sala de aula' (COELHO, 2010). Esse lema faz sentido no contexto da escola em tempo integral somente se a sala de aula for concebida como espaço de inovações pedagógicas; do contrário, ir além dos muros da escola pode significar uma reprodução de um olhar restrito sobre as potencialidades educativas da cidade. Isso pode reforçar a ideia de que a escola é a única instituição que educa.

O Programa Escola Integrada visa ampliar a função da escola com experiências desencadeadoras do desenvolvimento humano, social e cultural de crianças, adolescentes e jovens belorizontinos (SECRETARIA MUNICIPAL DE EDUCAÇÃO, 2007) e propõe manifestações culturais que interpretamos como práticas de lazer, as quais englobam as diversas linguagens, expressões e interesses das pessoas. A partir desse julgamento, construímos o argumento de que o Programa Escola Integrada dá pistas de suas interfaces com o lazer. Além dessa constatação, o programa apresenta o lazer como integrante das ações educativas fundamentado nas proposições do Mais Educação que esclarece:

Atividades baseadas em práticas corporais e lúdicas através de oficinas esportivas promotoras de práticas de sociabilidade, com ênfase no resgate da cultura local bem como o fortalecimento da diversidade cultural. No seu desenvolvimento deve prevalecer o sentido lúdico, a livre escolha na participação e a construção pelos próprios sujeitos envolvidos de valores e significados da prática dessas atividades, com criticidade e criatividade. Devese ressaltar o duplo aspecto educativo do esporte e do lazer; a possibilidade de educar para e pelo esporte e lazer. Isso significa o acesso ao conhecimento de novas práticas esportivas e de lazer e, as reflexões resultantes dessas práticas. (MINISTÉRIO DA EDUCAÇÃO, 2009, p. 11).

Os apontamentos desse macrocampo revelam categorias consideráveis na construção conceitual de lazer, que são o caráter lúdico, tratado como eixo principal das experiências de lazer, a livre vontade e o desenvolvimento. O sentido lúdico mencionado não tem o seu significado explicitado, o que é comum na produção sobre o lazer no Brasil em que o enunciado é impregnado de imprecisões (MARCELLINO, 1990; BRACHT, 2003). O sociólogo Joffre Dumazedier, cuja produção teórica influenciou os estudos do lazer no Brasil, destaca a livre escolha associada à liberação de obrigações e a função de desenvolvimento 
como pertencentes a um sistema de caracteres específicos na constituição do lazer, contemplados no caráter liberatório e pessoal, respectivamente (GOMES, 2004b).

Nessa perspectiva, é interessante destacar que tanto as atividades de lazer quanto as esportivas são apresentadas sob um caráter duplamente educativo. Em relação ao lazer, essa relação é reconhecida por Marcellino (1987) e Requixa (1990) que compartilham da ideia do duplo aspecto educativo do lazer, fundamentado como meio e objeto de educação, ou seja, educação pelo lazer e para o lazer. Como um processo educativo, o lazer torna possível a vivência, intervenção, aprendizagem, sensibilização, ludicidade e mudança na percepção da realidade social. O lazer, então, é apresentado no Programa Mais Educação e nos demais como um campo de ação pedagógica.

Nesse sentido, pensamos que analisar as concepções de lazer e educação na trajetória política do programa pode contribuir para o debate necessário sobre a temática escola em tempo integral e suas concepções.

\section{Educação e Lazer na Simbiose de Contextos}

No caso do Programa Escola Integrada, as influências surgem das agências em rede: Prefeitura de Belo Horizonte (PBH), Fundação Itaú Social e o Centro de Estudos e Pesquisas em Educação, Cultura e Ação Comunitária (CENPEC). A primeira constitui-se como a instância de personalidade jurídica, que possui certa autonomia administrativa e estabelece seus processos legislativos. A Fundação Itaú Social é um programa de responsabilidade social empresarial do Banco Itaú que atua na formulação de políticas públicas na área da educação e de avaliação de projetos sociais e exerce patrocínio recomendado por agências multilaterais. Por fim, o CENPEC que estabelece vínculos com a Fundação Itaú Social para prestar serviços de monitoramento e avaliação da proposta política. Os dois últimos, uma instituição privada e uma organização da sociedade civil, se unem à UNESCO no apoio aos projetos socioeducativos complementares à escola. No universo de influências, há uma interação dialética entre o global e o local, e Mainardes (2006, p. 52) revela que "a globalização promove a migração de políticas, mas essa migração não é uma mera transposição e transferência, pois as políticas são recontextualizadas dentro de contextos nacionais específicos".

Nesse movimento de influências foram identificadas agências de competências econômicas, de interesses civis e públicos. A articulação dessas instituições, autodenominadas parceiras, é encadeada num cenário sociopolítico e econômico traçado no início deste trabalho. É nesse cenário que agências multilaterais orientam reformas educacionais. 
Para Saviani (2007), a lógica do compromisso firmado pelas agências financeiras é de uma pedagogia por resultados; com isso, o governo se equipa de instrumentos de avaliação do desempenho dos alunos, que serve de parâmetros para se ajustar às exigências desses atores.

É, pois, uma lógica de mercado que se guia, nas atuais circunstâncias, pelos mecanismos das chamadas 'pedagogia das competências' e 'qualidade total'. Esta, assim como nas empresas, visa obter a satisfação total dos clientes e interpreta que, nas escolas, aqueles que ensinam são prestadores de serviço; os que aprendem são clientes e a educação é um produto que pode ser produzido com qualidade variável. (SAVIANI, 2007, p. 1253).

Entendemos que essa abordagem se faz também presente na dinâmica das políticas educacionais, pois há alternativas de financiamentos e financiadores privados para constituir uma infraestrutura do setor público. Compreendemos, porém, que na área educacional as reformas também são resultantes de uma reflexão dos processos sociais. Os professores e demais profissionais que atuam na escola promovem ações que reconfiguram as políticas. Portanto, o resultado dessa correlação de forças pode manifestar a tendência para a transformação social qualitativa anunciando a presença da cultura ou para a manutenção da ordem que aproxima a educação do mercado. Ball (2004) estabelece que a educação orienta-se para um 'quase mercado', o que contribui para pensar nos serviços sociais como formas de produção. O autor revela que categorias como desempenho, metas, gerencialismo, resultados estão presentes na educação contemporânea e refletem características do setor econômico.

Diante da análise proposta percebemos que há legitimação de uma linguagem empresarial em sobreposição ao discurso de justiça e igualdade no documento Plano Estratégico BH 2010-2030. Os resultados esperados do Programa Escola Integrada referem-se ao aumento do atendimento aos estudantes, à maior participação da comunidade escolar e à construção, reforma e ampliação dos prédios escolares. No Plano Estratégico, há outro projeto sustentador da educação que faz referência à qualidade da educação medida por índices, à saúde dos alunos e ao reforço escolar. É relevante ressaltar que os projetos que sustentam a área da Educação têm como metas a expansão de números de vagas, acesso e a permanência na escola, reformas prediais, variação de indicadores quantitativos, assistência à saúde e alimentação dos alunos e o reforço escolar.

Embora compreendamos que as metas estabelecidas são favoráveis à escola, acreditamos que não são suficientes para garantir o direito à educação de qualidade. Há fatores relacionados à formação permanente do professor, à valorização do trabalho docente, à gestão compartilhada que são necessários a um processo educacional qualificado e à garantia desse direito. 
O texto do documento também aponta como uma das estratégias de desenvolvimento da cidade "promover o salto na qualidade da educação e elevar o nível de escolaridade média da população, baseado em um sistema eficiente e orientado para resultados" (PREFEITURA BELO HORIZONTE, 2010, p. 29). Assim, a qualidade da educação fundamenta-se como elemento indispensável à competição internacional por capitais produtivos, financeiros e humanos. Essa abordagem indica que a educação está projetada sob a base do sistema global e econômico, e sua qualidade é referendada pela eficiência/eficácia e resultados. Ball (2002) e Shiroma et al. (2011) estabelecem que as políticas educacionais, diante das reformas atuais, tratam o desempenho (individual ou institucional) como medida de produtividade ou mostras de qualidade. Nesse sentido, as reformas transformam o trabalho das instituições educativas em resultados e formas de qualidade, e os incentivos profissionais são vinculados às medidas de desempenho.

Essa lógica contribui para pensar nos serviços sociais, como educação e lazer, enquanto forma de produção, o que pode levar ao estreitamento das relações do público e privado e à alteração de valores e da cultura. Ao tratar de cultura, consideramos como fundamental que todos os envolvidos nas práticas escolares e de lazer se percebam sujeitos produtores dela, e não como clientes consumidores.

As representações do lazer, no Plano Estratégico, estão relacionadas às potencialidades econômicas do turismo em Belo Horizonte e aos equipamentos públicos. O foco de ações da Prefeitura de Belo Horizonte (2010, p. 58) é "ampliar as perspectivas de turismo de lazer e negócios de porte médio em Belo Horizonte, visando consolidar a cidade como destino turístico”. Aponta, ainda, melhorias nas condições de lazer através de reforma e adequação ao uso de equipamentos públicos.

Uma visão do lazer articulada somente às questões de infraestrutura, manutenção e reforma de equipamentos e à atividade em si não reflete uma percepção ampliada para políticas de lazer. Segundo Marcellino (1987), o tempo e o espaço disponível são necessários, mas não são suficientes para o aproveitamento do lazer como elemento de desenvolvimento de atitudes críticas em relação às esferas da vida pessoal e social. Uma política de lazer deve, também, possibilitar a apropriação dos espaços de lazer, ou seja, considerar os equipamentos, tempos, atividades, animação, aspectos da mobilidade na cidade, pertencimento aos espaços, os sujeitos. Portanto, é necessária a oferta dos equipamentos públicos, porém acrescida das possibilidades de acesso e democratização embasadas na política cultural.

Parafraseando Chauí (1995), a política cultural é interpretada como cidadania cultural, ou seja, as pessoas da escola são sujeitos sociais, políticos e 
culturais. Assim, a cidadania cultural está intrinsecamente relacionada ao fortalecimento da cultura política, que permite que os sujeitos conheçam e percebam as tramas das desigualdades, das exclusões, das diferenças. Porém compartilhamos com Cavaliere (1999) a ideia de que as experiências brasileiras de ampliação do tempo escolar, principalmente na esfera pública, nem sempre contemplam essa perspectiva de formação cultural, visto os entraves da realidade social repleta de desigualdades, a qual, por vezes, é mascarada numa escola despolitizada que se desvincula da vida que corre fora dela.

No caso do Programa Escola Integrada, a simbiose de contextos sugere que a intenção dessa intervenção política é o enfrentamento da crise do fracasso escolar, revelada pelos índices de avaliação de rendimento e de fluxo (aprovação, repetência e evasão) dos alunos. Tais textos, produtos e produtores das orientações do programa, anunciam uma concepção de educação como direito, como processo de escolarização ditado pelo acesso e permanência. Entretanto, pensar que a educação se traduz somente no acesso e permanência é restrito, pois isso é condição fundamental para o processo de escolarização. Para abarcar uma discussão conceitual ampla é necessário refletir a função da escola e o papel dessa instituição na e para a sociedade. É preciso, ainda, reconhecer que o espaço escolar é uma das esferas possíveis, e não única, de aprendizagem que estabelece vínculos com a cultura. Nessa perspectiva, o lazer e a escola são reconhecidos como esferas de desenvolvimento de conhecimentos e habilidades que subsidiem um fortalecimento social, pessoal e cultural. Assim, o lazer apresenta-se como esfera de aprendizagem e é concebido por seu aspecto duplamente educativo, a educação para e pelo lazer.

De acordo com Marcellino (1987), a maioria dos estudiosos reconhece o duplo aspecto educativo do lazer, embora os enfoques dados a esse tratamento da relação lazer/educação sejam variados. Para o autor, os estudiosos do lazer enfatizam tanto valores funcionalistas ${ }^{10}$, quanto valores como desenvolvimento pessoal e social. Diante disso, a compreensão da relação entre lazer e educação por meio das concepções que perpassam as diretrizes torna-se relevante para evidenciar os valores manifestados nas proposições da Escola Integrada e assimilados em suas práticas.

\footnotetext{
${ }^{10} \mathrm{~A}$ visão funcionalista do lazer compreende as abordagens: romântica (traduzida pela nostalgia da volta ao passado dos valores de família, juventude, modos de vida de uma sociedade tradicional), moralista (apresentada numa perspectiva de ordem e segurança social), compensatória (referindo-se à oposição entre o trabalho moderno de caráter alienado, mecânico e fragmentado e a realização pessoal) e utilitarista (abordada como função de recuperação da força de trabalho e como instrumento de desenvolvimento). Marcellino (1987) defende que, por vezes, a perspectiva funcionalista mascara sua intenção de manutenção do status quo através de "um falso humanismo" (MARCELLINO, 1987, p. 39).
} 


\section{Considerações Finais}

Neste estudo, procuramos compreender as concepções de educação e lazer que permeiam os documentos referentes ao Programa Escola Integrada, traçando os processos históricos, políticos e culturais que condicionam as políticas educacionais e ressaltando os contextos de influência e da produção de textos da política. A análise fundamentada no ciclo de políticas apresentou instrumentos para uma abordagem crítica da trajetória política e a busca de princípios explicativos para os objetos lazer e educação interpretados nos documentos referidos.

Os documentos da Escola Integrada anunciam a garantia do acesso e permanência das crianças e jovens na escola, porém interpretamos que a educação não se apresenta como direito. Partimos do princípio de que, apesar desses aspectos constituírem o direito à educação, são insuficientes para defini-la como tal. É necessário também ampliar para a universalização e a qualidade das aprendizagens, possibilitando uma formação, de fato, integral. Entendemos, também, que o lazer abordado nos textos do programa apresenta-se restrito à visão de construção e manutenção de equipamentos e à atividade em si. Tal perspectiva distancia-se da lógica que apresenta o lazer como esfera de formação e tratado como espaço pedagógico, pois entendemos que as vivências possibilitam aprendizagens a respeito das representações de mundo, de sociedade, de sujeito e expõem em nosso cotidiano um conjunto de valores, de saberes, de formas de conviver ensinados por meio delas. Nesse sentido, é necessário ampliar a visão de lazer construindo práticas educativas que não se restrinjam a produtos finais a serem consumidos.

As concepções de educação e lazer apropriadas pelo Programa Escola Integrada indicam características funcionalistas, as quais, apesar de não as considerarmos negativas, possuem uma lógica não deve ser exclusivamente norteadora das práticas, mas necessitam que a compreensão de lazer e educação tangencie a função social de produção cultural e espaço de convivências das culturas. As concepções de lazer e educação podem orientar processos educativos de conservação ou inovação, considerando os sujeitos (alunos e profissionais) como agentes sociais.

Desse modo, compreendemos que evidenciar as concepções de lazer e educação e suas interfaces não direciona para um ajustamento da política, e sim para a reflexão da complexidade desses fenômenos para, então, encontrar caminhos que estabeleçam outra ordem. Nossas reflexões dão conta de que a escola, ao ter suas funções ampliadas e reconhecendo as relações dialéticas de lazer e educação, pode trilhar o caminho do controle social e/ou do desenvolvimento democrático e emancipatório, podendo contribuir para o enfrentamento das desigualdades educacionais e culturais. 


\section{Referências}

AKKARI, A. Internacionalização das políticas educacionais: transformações e desafios. Petrópolis: Vozes, 2011.

ANTUNES, A.; PADILHA, P. R. Educação cidadã, educação integral: fundamentos e práticas. São Paulo: Editora e Livraria Instituto Paulo Freire, 2010.

BALL, S. Sociologia das políticas educacionais e pesquisa critico-social: uma revisão pessoal das políticas educacionais e da pesquisa em política educacional. Currículo sem fronteiras, v. 6, n. 2, p. 10-32, jul./dez. 2006.

BALL, S. Performatividade, privatização e o pós-Estado do bem-estar. Educação \& Sociedade, Campinas, v. 25, n. 89, p. 1105-1126, set./dez. 2004. DOI: 10.1590/S010173302004000400002

BALL, S. O que é política? Textos, trajetórias e caixas de ferramentas. In: BALL, S. Education reform a critical and post-structural approach. Philadelphia: Open University Press, Buckingham, 1994. p. 14-27.

BELO HORIZONTE. Escola Integrada. Disponível em: <http://www.portal.pbh.gov. br>. Acesso em: 03 abr. 2010.

BETHELL, L. Política no Brasil: de eleições sem democracia a democracia sem cidadania. In: BETHELL, L. (Org.) Brasil: fardo do passado, promessa do futuro. Rio de Janeiro: Civilização Brasileira, 2002. p. 9-43.

BOMENY, H. A escola no Brasil de Darcy Ribeiro. Em Aberto, Brasília, v. 22, n. 80, p. 109120, abr. 2009.

BRASIL. Constituição da República Federativa do Brasil. 8. ed. São Paulo: Saraiva, 1993.

BRASIL. Ministério da Educação. Educação integral: texto referência para o debate nacional. Brasília: SECAD, 2008.

BRASIL. Portaria Normativa Interministerial $\mathrm{n}^{\circ}$ 17, de 24 de abril de 2007. Institui o Programa Mais Educação que visa fomentar a educação integral de crianças, adolescentes e jovens, por meio do apoio a atividades sócio-educativas no contraturno escolar. Diário Oficial da União, Brasília, DF, 26 abr. 2007.

CANDAU, V. M. Multiculturalismo e educação: desafios para a prática pedagógica. In: MOREIRA, A. F. B.; CANDAU, V. M. Multiculturalismo: diferenças culturais e práticas pedagógicas. 2. ed. Petrópolis: Vozes, 2008. p. 13-37.

CARDOSO, N. F. As políticas públicas de educação: adolescentes com trajetórias truncadas. 2012. 267 f. Tese (Doutorado em Educação) - Faculdade de Educação, Universidade de São Paulo, São Paulo, 2012.

CARNOY, M. Mundialização e reforma na educação: o que os planejadores devem saber. Brasília: UNESCO, 2002.

CARNOY, M.; LEVIN, H. Escola e trabalho no Estado capitalista. São Paulo, Cortez, 1993.

CARVALHO, J. M. Cidadania no Brasil: o longo caminho. 15. ed. Rio de Janeiro: Civilização Brasileira, 2012. 
CAVALIERE, A. M. Notas sobre o conceito de educação integral. In: COELHO, L. M. C. C. (Org.). Educação integral: estudos e experiências em processo. Petrópolis: FAPERJ, 2009. p. 41-52.

CAVALIERE, A. M. Tempo de escola e qualidade na educação pública. Educação \& Sociedade, Campinas, v. 28, n. 100 (Especial), p. 1015-1035, out. 2007. DOI: 10.1590/ S0101-73302007000300018

CHAUÍ, M. Cultura política e política cultural. Estudos Avançados, São Paulo, v. 9, n. 23, p. 71-84, jan./abr. 1995. DOI: 10.1590/S0103-40141995000100006

COELHO, J. S. Escola integrada. In: OLIVEIRA, D. A.; DUARTE, A. M. C.; VIEIRA, L. M. F. Dicionário: trabalho, profissão e condição docente. Belo Horizonte: UFMG/Faculdade de Educação, 2010. CD-ROM.

COELHO, L. M. C. C.; PORTILHO, D. B. Educação integral, tempo e políticas públicas: reflexões sobre concepções e práticas. In: COELHO, L. M. C. C. (Org.). Educação integral: estudos e experiências em processo. Petrópolis: FAPERJ, 2009. p. 89-99.

COORDENAÇÃO ESCOLA INTEGRADA. Arranjos educacionais possíveis para a educação integral. Salto para o futuro, Ano XVIII, boletim 13, p. 26-29, ago. 2008.

CURY, C. R. J. A Educação Básica no Brasil. Educação \& Sociedade, Campinas, v. 23, n. 80, p. 168-200, set. 2002. DOI: 10.1590/S0101-73302002008000010

DALLA POZZA, D. F.; REGINATO, G. D. O discurso da responsabilidade social: análise da produção noticiosa da Fundação Itaú Social. In: CONGRESSO DE CIÊNCIAS DA COMUNICAÇÃO NA REGIÃO SUL, 13., 2012, Chapecó. Anais... Chapecó, SC, 2012. p. 1-15. Disponível em: <http://www.intercom.org.br/papers/regionais/sul2012/resumos/ R30-0545-1.pdf>. Acesso em: 28 abr. 2013.

DALBERIO, M. C. B. Políticas educacionais e a gestão democrática na escola pública de qualidade. São Paulo: Paulus, 2009.

DEROUET, J. L. Justiça social e educação. In: OLIVEIRA, D. A.; DUARTE, A.; VIEIRA, L. M. F. (Orgs.). Dicionário: trabalho, profissão e condição docente. Belo Horizonte: UFMG/ Faculdade de Educação, 2010. CD-ROM.

DUARTE, A. Políticas educacionais e o trabalho docente na atualidade: tendências e contradições. In: DUARTE, A.; OLIVEIRA, D. A. (Orgs.). Políticas públicas e educação: regulação e conhecimento. Belo Horizonte: Fino Traço, 2011. p. 161-182.

DUBET, F. A escola e a exclusão. Cadernos de Pesquisa, São Paulo, n. 119, p. 29-45, jul. 2003. DOI: $10.1590 /$ S0100-15742003000200002

FARIA FILHO, L. M.; VIDAL, D. G. Os tempos e os espaços escolares no processo de institucionalização da escola primária no Brasil. Revista Brasileira de Educação, Rio de Janeiro, n. 14, p. 19-35, maio/ago. 2000. DOI: 10.1590/S1413-24782000000200003

FLEURY, S. Políticas sociais. In: OLIVEIRA, D. A.; DUARTE, A.; VIEIRA, L. M. F. (Orgs.). Dicionário: trabalho, profissão e condição docente. Belo Horizonte: UFMG/Faculdade de Educação, 2010. CD-ROM.

GADOTTI, M. Educação integral no Brasil: inovações e processo. São Paulo: Editora e Livraria Instituto Paulo Freire, 2009. 
GIROUX, H. A escola crítica e a política cultural. 3. ed. São Paulo: Cortez Autores Associados, 1992.

HÖFLING, E. M. Estado e políticas (públicas) sociais. Cadernos Cedes, Campinas, ano XXI, n. 55, p. 30-41, nov. 2001. DOI: 10.1590/S0101-32622001000300003

LDBEN. Lei de Diretrizes e Bases da Educação Nacional. Lei n. 9.394 de 20 de dezembro de 1996. Disponível em: < http://www.planalto.gov.br/ccivil_03/leis/19394.htm>. Acesso em: 28 abr. 2010.

MAINARDES, J. Abordagem do ciclo de políticas: contribuições para a análise de políticas educacionais. Educação \& Sociedade, Campinas, v. 27, n. 94, p. 47-69, jan./abr. 2006. DOI: 10.7867/1809-0354.2006v1n2p94-105

MAINARDES, J; MARCONDES, M. I. Entrevista com Stephen Ball: um diálogo sobre justiça social, pesquisa e política educacional. Educação \& Sociedade, Campinas, v. 30, n. 106, p. 303-318, jan./abr. 2009. DOI: 10.1590/S0101-73302009000100015

MARCELLINO, N. C. Lazer e educação. Campinas: Papirus, 1987.

MARSHALL, T. Cidadania e classe social In: MARSHALL, T. H. Cidadania, classe social e status. Rio de Janeiro: Zahar, 1967. p. 57-114.

MAURÍCIO, L. V. Escritos, representações e pressupostos da escola pública de horário integral. In: MAURÍCIO, L. V. (Org.). Educação integral e tempo integral. Em Aberto, Brasília, v. 22, n. 80, p. 15-31, abr. 2009.

MINISTÉRIO DA EDUCAÇÃO. Manual de Educação Integral. Disponível em: <ftp:/ / ftp.fnde.gov.br/web/pdde/manual_pdde_2009_escola_integral.pdf>. Acesso em: 28 abr. 2011.

MENEZES, J. S. S. Educação integral e tempo integral na educação básica: da LDB ao PDE. In: COELHO, L. M. C. C. (Org.). Educação Integral: estudos e experiências em processo. Petrópolis: FAPERJ, 2009. p. 69-87.

MORAES, J. D. Educação Integral: uma recuperação do conceito libertário. In: COELHO, L. M. C. C. Educação integral: estudos e experiências em processo. Petrópolis: FAPERJ, 2009. p. 21-39.

MOREIRA, A. F. B. A recente produção científica sobre currículo e multiculturalismo no Brasil (1995-2000): avanços, desafios e tensões. Revista Brasileira de Educação, Rio de Janeiro, n. 18, p. 65-81, set./dez. 2001. DOI: 10.1590/S1413-24782001000300007

MOREIRA, A. F. B. Propostas curriculares alternativas: limites e avanços. Educação \& Sociedade, ano XXI, n. 73, p. 109-138, dez. 2000. DOI: 10.1590/S0101-73302000000400009

OLIVEIRA, D. A. Política educacional. In: OLIVEIRA, D. A.; DUARTE, A.; VIEIRA, L. M. F. (Orgs.). Dicionário: trabalho, profissão e condição docente. Belo Horizonte: UFMG/ Faculdade de Educação, 2010a. CD-ROM.

OLIVEIRA, D. A. Trabalho docente. In: OLIVEIRA, D. A.; DUARTE, A.; VIEIRA, L. M. F. (Orgs.). Dicionário: trabalho, profissão e condição docente. Belo Horizonte: UFMG/ Faculdade de Educação, 2010b. CD-ROM.

OLIVEIRA, D. A. Das políticas de governo a política de estado: sobre a atual agenda educacional brasileira. Educação \& Sociedade, Campinas, v. 32, n. 115, p. 323-337, abr./ jun. 2011. DOI: 0.1590/S0101-73302011000200005 
PAGNI, P. A. Anísio Teixeira - Experiência reflexiva e projeto democrático: a atualidade de uma filosofia da educação. Petrópolis: Vozes, 2008.

PARO, V. H. Educação integral em tempo integral: uma concepção de educação para a modernidade. In: COELHO, L. M. C. C. (Org.). Educação integral: estudos e experiências em processo. Petrópolis: FAPERJ, 2009, p. 13-20.

PARO, V. H. Transformação social e educação escolar. In: PARO. V. H. (Org.). Administração escolar: introdução crítica. 14. ed. São Paulo: Cortez, 2006. p. 81-122.

PETITAT, A. O surgimento dos sistemas escolares estatais: premissas e condições. In: PETITAT, A. (Org.). Produção da escola, produção da sociedade: análise sócio-histórica de alguns momentos decisivos da evolução escolar no ocidente. Porto Alegre: Artes Médicas, 1994. p. 141-169.

PREFEITURA DE BELO HORIZONTE. Escola Plural proposta político-pedagógica da rede municipal de educação de Belo Horizonte. 3 ed. Belo Horizonte, 2002.

PREFEITURA DE BELO HORIZONTE. Plano estratégico de Belo Horizonte 20102030. Disponível em: <http://www.bhmetaseresultados.com.br/sites/all/themes/metas/ pdf/ planejamento_2030.pdf>. Acesso em: 28 jul. 2011.

REZENDE, M.; BAPTISTA, T. W. F. A análise da política proposta por Ball. In: MATTOS, R. A.; BAPTISTA, T. W. F. (Org.). Caminhos para análise das políticas de saúde, 2011. p. 173-180. Disponível em: <www.ims.uerj.br/ccaps>. Acesso em: 03 dez. 2012.

RIBEIRO, S. P. O lazer na política pública de esporte: uma análise do programa Segundo Tempo. 2012. 148 f. Dissertação (Mestrado em Estudos do Lazer) - Escola de Educação Física Fisioterapia e Terapia Ocupacional da Universidade Federal de Minas Gerais, Belo Horizonte, 2012.

SABOYA, M. G. F. Programa Mais Educação: uma proposta de educação integral e suas orientações curriculares. 2012. 162 f. Dissertação (Mestrado em Educação) - Centro de Ciências Humanas e Sociais, Universidade Federal do Estado do Rio de Janeiro, Rio de Janeiro, 2012.

SALAMA, P.; VALIER, J. A via liberal de combate à pobreza. In: SALAMA, P.; VALIER, J. Pobrezas e desigualdades no terceiro mundo. São Paulo: Nobel, 1997. p. 103-128.

SALGADO, J. A. Desigualdade social. In: OLIVEIRA, D. A.; DUARTE, A.; VIEIRA, L. M. F. (Orgs.). Dicionário: trabalho, profissão e condição docente. Belo Horizonte: UFMG/ Faculdade de Educação, 2010. CD-ROM.

SARAIVA, A. L.; COSTA, B. L. D. Escola Plural: reflexos sobre a produção de políticas educacionais..Revista Pensar BH, Belo Horizonte, n. 26, p. 23-27, jun. 2010. DOI: 10.1590/ S0101-73302007000300027

SAVIANI, D. O Plano de Desenvolvimento da Educação: análise do projeto do MEC. Educação \& Sociedade, Campinas, v. 28, n. 100 (Especial), p. 1231-1255, out. 2007. DOI: 10.1590/S0101-73302007000300027

SHIROMA, E. O.; GARCIA, R. M. C.; CAMPOS, R. F. Conversão das 'almas' pela liturgia da palavra: uma análise do discurso do movimento Todos pela Educação. In: BALL, S.; MAINARDES, J. (Orgs.). Políticas educacionais: questões e dilemas. São Paulo: Cortez, 2011. p. 222-248. 
SECRETARIA MUNICIPAL DE EDUCAÇÃO. Proposições curriculares ensino fundamental: textos introdutórios. Belo Horizonte: Secretaria Municipal de Educação/ Prefeitura Belo Horizonte, 2010. 53 p.

SECRETARIA MUNICIPAL DE EDUCAÇÃO. Projeto Escola Integral. Belo Horizonte: Secretaria Municipal de Educação/Prefeitura Belo Horizonte, 2007. 15 p. (Impresso).

SOARES, J. F. Qualidade da educação. In: DAYRELL, J. et al. Família, escola e juventude: olhares cruzados Brasil-Portugal. Belo Horizonte: Editora UFMG, 2012. p. 231-254.

TONET, I. Educação e formação humana. Revista do Centro de Educação e Letras, Foz do Iguaçu, v. 8, n. 9, p. 9-21, $2^{\circ}$ semestre, 2006.

Recebido em 04/09/2013

Versão final recebida em 26/06/2014

Aceito em 20/08/2014 